\title{
Sympathetic nerve function status and their relationships with ovarian hormones in healthy young women
}

\author{
Latifa Afrin Dill Naher ${ }^{1}$, Noorzahan Begum ${ }^{2}$, Sultana Ferdousi ${ }^{3}$
}

\begin{abstract}
Background: Alteration of sympathetic nerve activity during different phases of menstrual cycle in healthy young women, has been found related with phasic fluctuation of ovarian hormones. Objective: To observe relation of sympathetic nerve function status with estrogen and progesterone during follicular and luteal phases of menstrual cycle in healthy young women. Methods: This cross sectional study was carried out in the Department of physiology of BSMMU, Dhaka from $1^{\text {st }}$ January to $31^{\text {st }}$ December 2007. Thirty apparently healthy unmarried women with age 20 to 30 years were selected. Sympathetic nerve function was evaluated by 2 reflex tests, orthostatic test and sustained handgrip, during the three phases of menstrual cycle. Serum estrogen and progesterone were measured during follicular and luteal phases. Data were analyzed by One way ANOVA, an unpaired $t$ test and Pearson's correlation coefficient where applicable. Results: There were no significant significant differences among sympathetic nerve function parameters during three phases of menstrual cycle. Serum estrogen and progesterone showed non significant $(\mathrm{p}>0.05)$ relationship with sympathetic nerve function parameters. Conclusion: From this study it may be concluded that sympathetic nerve activity remains unaltered despite fluctuation of ovarian hormones in different phases of menstrual cycle in healthy young women.
\end{abstract}

Key Words: Ovarian hormone, sympathetic nerve activity.

J Bangladesh Soc Physiol. 2016, June; 11(1): 13-17 For Authors Affiliation, see end of text.

http://www.banglajol.info/index.php/JBSP

\section{Introduction}

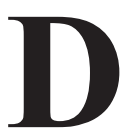

uring the childbearing age women have reduced risk of cardiovascular diseases than $\operatorname{man}^{1}$.Healthy young women having normal menstrual cycle is characterized by increased level of oestrogen secretion before ovulation followed by a sharp fall then secondary phase of secretion in the luteal phase. But during luteal phase both estrogen in moderate and progesterone hormone remain in high concentration $^{2}$. Very Few researches have been carried out on healthy young women to find out the relationship of sympathetic nerve activity and

Received 11th Oct. 2015; Accepted 13th Jan. 2016 ovarian hormones during different phases of menstrual cycle, where changes in ovarian hormone occur to a great extent. Some investigators observed increased sympathetic activity during luteal phase of menstrual cycle 1,5 . However, other investigators did not observe any change in sympathetic nerve function during luteal phase ${ }^{6}$. Some researchers observed greater sympathetic baroreflex sensitivity during mid luteal (high hormone) phase compared with the menstrual (low hormone) phase of a normal menstrual cycle ${ }^{7}$. Because of this conflicting reports, this study aimed to observe sympathetic 
nerve activity during different phases of menstrual cycle and their relationships with ovarian hormones in healthy young women.

\section{Methods}

This cross sectional study was carried out in the Department of physiology of BSMMU, Dhaka from $1^{\text {st }}$ January to $31^{\text {st }}$ December 2007 . A total number of thirty apparently healthy unmarried women with age ranged from 20 to 30 years were enrolled. They were studied during the menstrual, follicular and luteal phases of menstrual cycle All the subjects were having regular menstrual cycle and were free from Diabetes mellitus,renal failure, $\mathrm{BMI}>22.9 \mathrm{~kg} / \mathrm{m}^{2}$, menstrual abnormalities, any acute or chronic illness or any medication affecting CNS. The study Protocol was approved by the ethical committee of the department of Physiology BSMMU. The aim and objectives of the study were explained to the subjects in details and then written informed consent was taken. Resting SBP and DBP were measured during each 3 phases of menstrual cycle. Again, sympathetic nerve function was evaluated by 2 simple non invasive conventional autonomic nerve function tests such as fall in systolic blood pressure after standing and rise in diastolic blood pressure during sustained handgrip in three phases of a menstrual cycle. Three ml venous blood was collected to measure serum estrogen and progesterone level by during follicular and luteal phases of menstrual cycle. Hormone was not measured during menstrual phase as its secretion was negligible in quantity. Data was expressed as mean \pm SD. Data were analyzed by One way ANOVA, un paired t test and Pearson's correlation coefficient where applicable. The statistical analysis was done by SPSS program version-11.5. "p" value $<0.05$ was considered as significant.

\section{Results}

All the mean values of SBP and DBP in menstrual, follicular, luteal phase were not significantly different. (Figure 1).Mean \pm SD fall in systolic blood pressure after standing and rise in DBP after sustained handgrip in all groups were almost similar and no statistical $(\mathrm{p}>0.05)$ significant differences were observed. (Figure 2\&3)

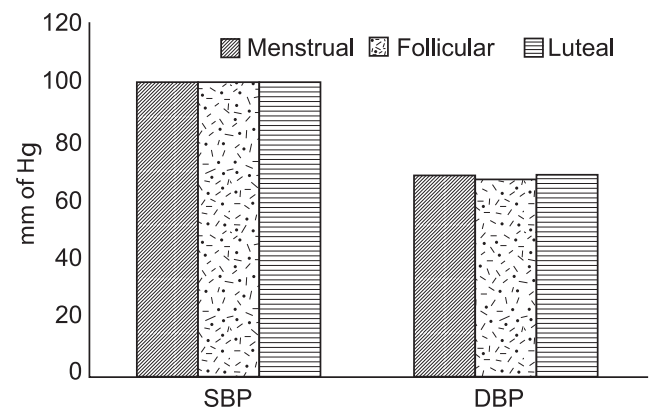

Figure 1: Resting SBP and DBP during 3 phases of menstrual cycle. No significant difference among the phases were noted.

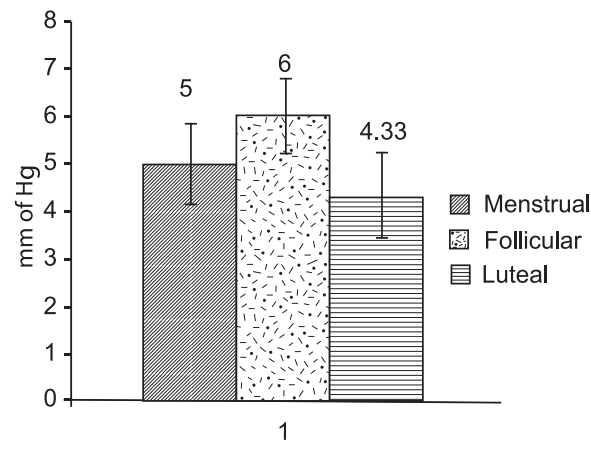

Figure 2: Fall in SBP after standing from lying during 3 phases of menstrual cycle. No significant difference among the phases were noted.

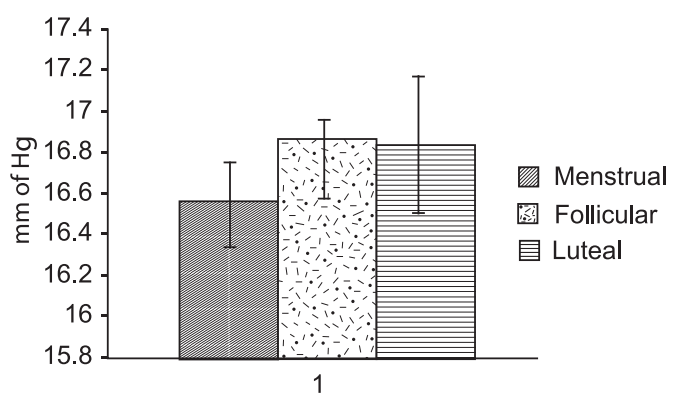

Figure 3: Rise of DBP during sustained handgrip during 3 phases of menstrual cycle. No significant difference among the phases were noted. 
Table I : Relationship of serum estrogen level with sympathetic nerve function parameters in different groups $(\mathrm{n}=60)$

\begin{tabular}{|c|c|c|c|c|}
\hline \multirow[t]{2}{*}{ Parameters } & \multicolumn{2}{|c|}{ Follicular } & \multicolumn{2}{|c|}{ luteal } \\
\hline & $\mathrm{r}$ & $\mathrm{p}$ & $\mathrm{r}$ & $\mathrm{p}$ \\
\hline Fall in systolic blood pressure after standing ( $\mathrm{mm}$ of $\mathrm{Hg}$ ) & 0.033 & $0.864^{\mathrm{ns}}$ & -0.22 & 0.243 \\
\hline $\begin{array}{l}\text { Rise in diastolic blood pressure after sustained handgrip } \\
(\mathrm{mm} \text { of } \mathrm{Hg} \text { ) }\end{array}$ & -0.302 & $0.105^{\text {ns }}$ & 0.264 & 0.159 \\
\hline
\end{tabular}

Table-II : Relationship of serum progesterone level with sympathetic nerve function parameters in different groups $(n=60)$

\begin{tabular}{|c|c|c|c|c|}
\hline \multirow[t]{2}{*}{ Parameters } & \multicolumn{2}{|c|}{ Follicular } & \multicolumn{2}{|c|}{ Luteal } \\
\hline & $\mathrm{r}$ & $\mathrm{p}$ & $\mathrm{r}$ & $\mathrm{p}$ \\
\hline Fall in systolic blood pressure after standing $(\mathrm{mm}$ of $\mathrm{Hg}$ ) & -0.253 & $0.177^{\mathrm{ns}}$ & -0.019 & 0.920 \\
\hline $\begin{array}{l}\text { Increase in diastolic blood pressure after sustained handgrip } \\
(\mathrm{mm} \text { of } \mathrm{Hg})\end{array}$ & -0.027 & $0.888^{\mathrm{ns}}$ & 0.049 & 0.796 \\
\hline
\end{tabular}

Fall in systolic blood pressure after standing from lying position was positively correlated with serum estrogen in follicular but negatively correlated in luteal wheras negatively correlated with serum progesterone level in both follicular and luteal phase. The increase in diastolic blood pressure after sustained handgrip was negatively correlated with serum estrogen in follicular but positively correlated in luteal but with progesterone it was negatively correlated in follicular and positively correlated in luteal phase.(Table I \& II). However all these correlations were statistically not significant $(\mathrm{p}>0.05)$.

\section{Discussion}

In this study, high level of serum estrogen were observed in both follicular and luteal phases of menstrual cycle. Values of estrogen and progesterone were published in our previous article ${ }^{8}$. These results are consistent with the results observed by Edwards et al. ${ }^{9}$ and Tanaka et al. ${ }^{10}$. Again serum progesterone level during luteal phase was significantly higher than follicular phase. Similar results had been observed by Sato et al. ${ }^{1}$, Edwards et al. ${ }^{9}$ and Tanaka et al. ${ }^{10}$.

Again, resting systolic and diastolic blood pressures among the three phases of menstrual cycle of the present series of premenopausal women were within normal ranges and no significant differences have been observed among the phases that indicate no altered sympathetic nerve activity during these phases of menstrual cycle. Greenberg et al. ${ }^{11}$, Hirshoren et al. ${ }^{12}$ and Pai et al. ${ }^{13}$ also have demonstrated similar findings. Again, sato et al. ${ }^{1}$ observed similar results when compared SBP and DBP during follicular and luteal phases of menstrual cycle. However, Mehta and Chakrabarty 5 demonstrated significantly higher values of systolic blood pressure during luteal phase than other phases of menstrual cycle but there was no change in diastolic blood pressures. Again, 
another group of investigators observed decreased values of both systolic and diastolic blood pressure during luteal phase of menstrual cycle ${ }^{9}$.

In our study values of fall in systolic blood pressure after standing and rise in diastolic blood pressure during sustained handgrip were not significantly different among the three phases of menstrual cycle. This result is in consistent with the findings observed by Leicht, Hirningand Allen ${ }^{6}$, but they have used power spectral analysis of HRV to detect sympathetic nerve activity. However, some investigators have got increased sympathetic nerve activity during luteal phase in comparison to follicular phase by using power spectral analysis of HRV ${ }^{1,4}$. Again, Mehta and Chakrabarty ${ }^{5}$ have observed increased sympathetic activity during luteal phase than other phases of menstrual cycle.

In this study, observed relationships between serum estrogen and sympathetic nerve function parameters were not statistically significant in both follicular and luteal phases of menstrual cycle. Similar findings were obtained by tamaka matsumoto $^{14}$ who used HRV on eumenorrheic women having no premenstrual symptoms. However, in our study we did not consider premenstrual symptoms while selecting subjects. Again Leicht, Hirning and Allen demonstrated significant relationship between serum estrogen and HRV at ovulation ${ }^{6}$.

In this group of women we did not observe significant relationship between progesterone and sympathetic nerve function parameters. However, Minson et. al. found that sympathetic baroreflex sensitivity may be enhanced by estrogen but progesterone may antagonize this effect in young women ${ }^{2}$.

The under lying biomechanisms of estrogen and progesterone on sympathetic nerve function remains enigmatic. Heesch, Rogers howed that progesterone reduces sympathetic baroreflex sensitivity ${ }^{15}$ but in 1998 He X-R, Wang, Crofton

16 observed in animal studies that estrogen enhances sympathetic baroreflex sensitivity. Similar observations also demonstrated by Christopher et. al. in $2000^{2}$ who observed that estrogen augment sympathetic baroreflex sensitivity but progesterone antagonizes this activity in young women. Heesch, Rogers in $1995^{15}$; Heesch, Folly in 2001 suggested that progesterone in high concentration potentiate the GABA mediated baroreflex sympatho-inhibition within RVLM ${ }^{17-18}$.

\section{Conclusion}

From this study it may be concluded that sympathetic nerve activity may not change despite fluctuation of ovarian hormones in different phases of menstrual cycle in healthy young women.

\section{Conflict of interest: None}

\section{Acknowledgement}

The authors thank all the participants of this study. This study was partially funded by research grant from Bangladesh University Grant Commission. The funding agency has no role in designing, data collection of the study and manuscript submission for publication.

\section{Author affiliations}

1. *Latifa Afrin Dill Naher,Associate Professor of Physiology,Prime Medical College.Rangpur. Email:afrin_latifa2007@yahoo.com

2. Noorzahan Begum,Professor,Department of Physiology,Bangabandhu Sheikh Mujib Medical University Shahbag,Dhaka-1000, Bangladesh.

3. Sultana Ferdousi,Associate Professor,Department of Physiology,Bangabandhu Sheikh Mujib Medical University,Shahbag, Dhaka-1000,Bangladesh.

*Corresponding author

\section{References}

1. Neves et al. VFC, Silva de Sa, Gallo Jr L, Catai A M, Martins L E B, Crescencio J C, Perpetuo N M, Silva E. Autonomic modulation of heart rate of young and postmenopausal women undergoing estrogen therapy. Braz J Med Biol Res. 2007; 40(4): 491-499.

2. Ganong WF. Review of Medical Physiology.22 $2^{\text {nd }}$ ed. USA :McGraw-Hill; 2005. 
3. Minson CT, Halliwill JR, Young TM, Joyner MJ. Influence of the menstrual cycle on sympathetic activity, baroreflex sensitivity and vascular transduction in young women. Circulation 2000;101:862-868.

4. Princi T, Parco S, Accardo A, Radillo O, De Seta F, Guaschino S. Parametric evaluation of heart rate variability during the menstrual cycle in young women. Biomed Sci Instrum. 2005;41:340-345.

5. Yildirir; A, Kabakci G, Akgul E, Tokgozoglu L, Oto A. Effects of menstrual cycle on cardiac autonomic innervation as assessed by heart rate variability. Ann Noninvasive Electrocardiol 2002; 7(1):60-63.

6. Mehta V, Chakrabarty AS. Autonomic functions during different phases of menstrual cycle. Indian J Physiol Pharmacol. 1993; 37(1):56-8.

7. Leicht AS, Hirning DA, Allen GD. Heart rate variability and endogenous sex hormones during the menstrual cycle in young women. Exp Physiol 2003; 88(3):441446.

8. Sato N, Miyake S, Akatsu J, Kumashiro M. Power spectral analysis of heart rate variability in healthy young women during the normal menstrual cycle. Psychosom Med. 1995; 57:331-335

9. Naher LAD, Begum N, ferdousi S. Relationship Between Parasympathetic Nerve Function and Ovarian Hormones During Different Phases of Ovarian Cycle in Healthy Young Women. J Bangladesh Soc Physiol 2012 ;7(2):83-88.

10. Edwards N, Wilcox I, Polo OJ , Sullivan CE.Hypercapnic blood pressure response is greater during the luteal phase of the ovarian cycle. J Appl Physiol 1996; 81: 2142-2146.
11. Tanaka M, Sato M, Umehara S, Nishikawa T. Influence of menstrual cycle on baroreflex control of heart rate: comparison with male volunteers. Am J Physiol regul Integr Comp Physiol. 2003; 285:1091-1097.

12. Greenberg G, Imeson JD, Thomson SG and Mecade TW. Blood pressure and the menstrual cycle. Br J Obstet Gynecol. 1985; 92(10):1010-4.

13. Hirshoren N, Tzoran I, makrienko I, Edoute Y, Plawner MM, Itskovitz-Eldor J, Jacob G. Menstrual cycle effects on the neurohumoral and autonomic nervous systems regulating the cardiovascular system. J Clin Endocrinol Metab. 2002; 87(4):1569-1575.

14. Pai SR, Prajna P, D'souza UJA. A correlative study on blood pressure and lung function profile during different phases of menstrual cycle among Indian population. J Physiol Sci. 2004;19(2):30-34.

15. Matsumoto T, Ushiroyama T, Morimura M, Moritani T, Hayashi T, Suzuki T and Tatsumi N. Autonomic nervous system activity in the late luteal phase of eumenorrheic women with premenstrual symptomatology. J Psychosom Obstet Gynecol. 2006; 27(3):131-139.

16. Heesch CM, Rogers RC. Effects of pregnancy and progesterone metabolites on regulation of sympathetic outflow. Clin Exp Pharmacol Physiol. 1995;22:136-142.

17. He X-R, Wang W, Crofton JT, et al. Effects of 17B estradiol on sympathetic activity and pressor response to phenylephrine in ovarectomized rats. Am J Physiol. 1998;275:R1202-R1208.

18. Heeses CM, Foley CM. CNS effects of ovarian hormones and metabolites on neural control of circulation. Ann N Y Acad Sci. 2001; 940:348-360. 